
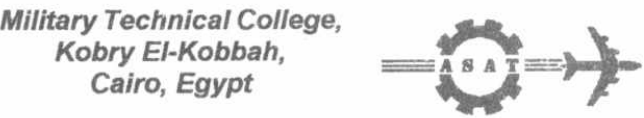

$9^{\text {th }}$ International Conference

On Aerospace Sciences \&

Aviation Technology

\title{
PERFORMANCE OF A BOREHOLE PUMP \\ IN VIEW OF \\ VARYING ITS RADIAL AND AXIAL CLEARANCES
}

\author{
A.A.E. Ghorap
}

\section{ABSTRACT}

A Pump is the heart of most industrial systems. To make these systems as efficient as possible, the pump must be selected properly to match the requirements of the water source, the water piping system as well as the industrial equipment. There is a real need to look at the borehole pump behavior and to modify its design for the sake of improving its characteristics.

In this research, a $1 \mathrm{~kW}$, three-stage, borehole pump was tested. Its impeller outer diameter was $11.7 \mathrm{~cm}$ with radial and axial clearances of $2 \mathrm{~mm}$ and $1 \mathrm{~mm}$, respectively. The impeller outer diameter was reduced to $11.3 \mathrm{~cm}$ and then to $10.9 \mathrm{~cm}$, for the same pump casing. The radial clearance between the impeller outlet and the pump casing was changed consequently. Hence, three radial clearances were tested, namely; $2 \mathrm{~mm}, 4 \mathrm{~mm}$ and $6 \mathrm{~mm}$, respectively. These radial clearances corresponded to clearance-impeller radius ratios of $3.4 \%, 6.8 \%$ and $10.2 \%$, respectively. The axial clearance, between the impeller outlet and the diffuser inlet, was varied three times, from $1 \mathrm{~mm}$ to $2 \mathrm{~mm}$ and then to $3 \mathrm{~mm}$ corresponding to clearance-impeller width ratios of $16.6 \%, 33.33 \%$ and $50 \%$, respectively.

The effect of varying the previously mentioned design parameters on the performance of borehole pumps was investigated. It airned at getting the radial and axial clearance values corresponding to optimum pump performance. The results revealed that; changing either the radial or the axial clearances or both has a remarkable effect on the pump performance. Within the tested range, the optimum combination found was; to run the pump at discharge values above the corresponding values at the normal operating point, with radial and axial clearances of $6 \mathrm{~mm}$ and $2 \mathrm{~mm}$ respectively. This corresponds to a radial clearance to impeller radius ratio of $10.2 \%$ and axial clearance to impeller width ratio of $33.33 \%$.

\section{KEY WORDS}

Borehole, pump, performance, radial, axial and clearance

•Lecturer, Dpt. of Mechanical Power Engineering. Ain Shams University, Cairo. Egypt 


\section{NOMENCLATURE}

\begin{tabular}{|c|c|c|}
\hline b & : Impeller outlet width & $\mathrm{mm}$ \\
\hline D & : Irnpeller outlet diameter & $m$ \\
\hline $\mathrm{H}$ & : Pump head & $\mathrm{m}$ \\
\hline k & : Correction factor & \\
\hline $\mathrm{N}$ & : Pump rotational speed & rpm \\
\hline $\mathrm{N}_{\mathrm{s}}$ & Pump specific speed $=(3.65 \mathrm{~N} \sqrt{\mathrm{Q}}) / \mathrm{H}^{3 / 4}$ & \\
\hline $\mathrm{P}$ & : Electric motor power & W \\
\hline Q & : Pump discharge & $\mathrm{m}^{3} / \mathrm{s}$ \\
\hline $\mathrm{R}$ & : Impeller outlet radius & $\mathrm{m}$ \\
\hline 川 & : Pump overall efficiency & \\
\hline$\rho$ & : Water density & $\mathrm{Kg} / \mathrm{m}^{3}$ \\
\hline$\delta$ & : Radial Clearance & $\mathrm{mm}$ \\
\hline$\Delta$ & : Axial Clearance & $\mathrm{mm}$ \\
\hline \multicolumn{3}{|c|}{ Subscribt } \\
\hline$n$ & \multirow{2}{*}{\multicolumn{2}{|c|}{$\begin{array}{l}\text { : Normal operating point } \\
\text { : Original }\end{array}$}} \\
\hline 0 & & \\
\hline \multicolumn{3}{|c|}{ Abbreviations } \\
\hline rc & : Radial clearance & \\
\hline & Axial clearance & \\
\hline
\end{tabular}

\section{INTRODUCTION}

Borehole pumps are sometimes called vertical turbine or deep) well pumps. They are considered a reliable option in water purnip. 19 , since they offer several advantages among the other types of centrifugal pumps. They are adapted for use in cased wells and where the water surface is below the practical limits of a centrifugal pump. Since the pump intake is continuously under water, priming is not of concern. As a result, priming is unnecessary, which makes it suitable for floating axplications. Also, a selfpriming feature is very desirable in areas where there are frequent electrical power outages or off-peak electrical price reductions ars available.

This pump type should be designed with a shat that car be readily raised and lowered to permit proper adjustment of the mpelle: position in the bowl. An adequate thrust bearing is also necessary to support the vertical shafting, the impeller, and the hydraulic thrust developed when the pump is in service. Such pumps are sometimes made with their own thrust bearings to allow for belt drive or for drive through a flexible coupling by a solid shaft motor, gear, or turbine. Dual-driven pumps usually employ an angle gear with a vertical motor mounted on its top. Liquid in a vertical turbine pump is guided into the impeller by the suction case or head. This may be a tapered section for attachment of a conical strainer or suction pipe, or it may be a bell mouth $[1,2]$.

Borehole pumps must have correct alignment between the punp and the power unit. Correct alignment is made easy by using a froad assembly that matches the motor 
and column pump assembly. It is very important that the well is straight and plumb. The pump column assembly must be vertically aligned so that no part touches the well casing. Spacers are usually attached to the pump column to prevent the pump assembly from touching the well casing. If the pump column does touch the well casing, vibration will wear holes in the casing. A pump column out of vertical alignment may also cause excessive bearing wear.

Scherer [3], revealed that the head assembly must be mounted on a good foundation at least 12 inches $(\sim 30 \mathrm{~cm})$ above the ground surface. A foundation of concrete provides a permanent and trouble-free installation. The foundation must be large enough to allow the head assembly to be securely fastened. The foundation should have at least 12 inches $(\sim 30 \mathrm{~cm})$ of bearing surface on all sides of the well.

Tinney [4] studied the cause of the serious damage to long column deep well pumps due to improper venting during start-up. He reveaied that it is usually necessary to install a combination vacuum-breaker/air-vent valve that will admit air into the pump column at a pre-determined rate that allows the water level in the column to sink slowly to the level of the underground water. Moreover, the valve piping should have provision for a restricting orifice that will permit the air pressure in the top of the column to increase and act as cushion when the pump is started. This trapped air can slow down the liquid rising up the pump discharge column. The size of the air exit orifice is critical, since the desired characteristic is to act as a throttle valve. Yet, does not permit the air pressure to build to a level that may exceed the maximum allowable surge pressure of the pump discharge head.

Alcock [5], in his article, found that there are benefits resulting from the ability to change pump speed to match the fluid production capacity of the well and thereby have continuous pumping. It eliminates the on-off operation and reduces the thrust wear on the pump and motor bearings. The pumping system efficiency is improved compared to cycling or throttled operation. Also, the possibility of cavitation is minimized, since frequent adjustment is possible to prevent pumping rate from exceeding the well's productive capacity. In addition, Alcock [4] found that the settling of solids, which damage the pump bearings and the accumulation of paraffins that impedes the flow, are minimized. Other benefits with variable speed drive, that the range of pumping capability of a particular pump is greatly expanded, so the need for pump changes to match well performance can be minimized and perhaps eliminated.

El-Sibaie [6], got another approach to the equations of reduced impeller diameters of radial flow centrifugal pumps. He found that the negligence of the variation in the outer impeller width and outlet vane angle of reduced impeller diameters, whatever this variation is slight, are the main causes of the departure from similarity.

In this research, investigations are carried out to test a three-stage borehole pump for the sake of improving its performance. These investigations were carried out while reducing the impeller diameter (changing the radial clearance), varying the axial clearance and noticing their effects on the pump overall behavior. It should be noted that, changing the radial clearance was performed by reducing the impeller diameter for the same pump casing. In this case, the change in clearance as a value is more pronounced than the impeller diameter reduction. Hence, the impact of the impeller 


\begin{abstract}
diameter reduction on the pump performance is negligible compared to the impact of
changing the radial clearance.
\end{abstract}

\title{
TEST APPARATUS
}

The test apparatus used, as shown in figure (1), consists of a three-stage borehole pump driven by a $1 \mathrm{~kW}$, three-phase electric motor, having a power factor of 0.9 , through a belt drive. The motor is driving the pump through pulley and belt with a ratio of pulleys diameter $1: 1$. The rotational speed of the motor was set to be approximately $1450 \mathrm{rpm}$; which is the same as the rotational speed of the borehole pump. This rotational speed was measured by a calibrated tachometer with an accuracy of $1 \%$. The values of the rotational speed were checked, at every single point in each run, to make sure that the speed is constant thrcughout the test.

The pump and the electric motor were fixed in a cylindrical viater container, $88 \mathrm{~cm}$ in height and $59 \mathrm{~cm}$ in diameter and the pump three stages wert completely submersed in the water as shown in the figure. A ball valve was installed on the delivery pipeline to control the flow out of the pump. The water flow rate was measured using a calibrated flow meter that was installea berors the discharge ball valve. The amount of water that passes the flow meter in a cettan period, measured using a stop watch, was recorded. The discharge pressure the borehole pump was measured using a calibrated bourdon pressure gatige fixed on the pump discharge line and before the discharge valve. The input volt and current to the electric motor were measured using a clamp meter and a volsneter. Readings of the power source were thoroughly checked in each reading to make sure that the fiequency and volt were constant during each run. Consequently, the rotational speed of both motor and pump remained constant. The maximum discharge that the fump can deliver, at full valve opening was found to be around 2hitsec. The maximum power required to operate the motor, while the discharge vaive is completely shut, was found to be
around 560 Watt.

The pump that is used in the tests has thrise-stage closed type impeliers mounted vertically on a line shaft as shown in figure (1). Figure (1-a) shows the pump cross sectional area with the impellers and the diffusers. Each impeller has an outer diameter of $11.7 \mathrm{~cm}$ and an outlet vidth of $5 \mathrm{~mm}$. The pump specific speed was found to be $\mathrm{N}_{\mathrm{s}}=40.18\left(\mathrm{Q}=0.0012 \mathrm{~m}^{3} / \mathrm{s}\right.$ \& $\mathrm{H}=7.65 \mathrm{~m}$ at the maximurn efficiency point). The bowl assembly consists of the suction case that is sometimes called the suction head, the discharge bowl, the intermediate bowls, the discharge case, the various bearings and miscellaneous parts such as kojs, impeller locking snap rings and the like. The column pipe assembly consists of the conmn pipe itself, the shafting above the bowl assembly, the shaft bearings and the cover pipe or bearing retainers. The pump is suspended from the driving head, which consists of the discharge elbow, the motor or driver and support. At the beginning of the suction pipe a strainer was installed for filtering the water before entering the pump. The change of the pump axial clearance was done by moving the mpelle locking snap ings $1 \mathrm{~mm}$ in the axial direction to increase the pump axial cleararce $1 \mathrm{~mm}$. Photcs 1,2 and 3 show the tested three-stage pump and the measuring instrumentation nounted on the pump
discharge line. 


\section{TEST METHODOLOGY}

The three impellers external diameters, of the three-stage borehole pump under investigation, were reduced resulting in a change in the pump radial clearance for the same pump casing. The radial clearance is the distance between the impeller outlet and the pump casing. First of all, the impeller outer diameter was $11.7 \mathrm{~cm}$ with radial clearance $\delta$ of $=2 \mathrm{~mm}$. This diameter was reduced to $11.3 \mathrm{~cm}$ and then to $10.9 \mathrm{~cm}$, respectively. This means three radial clearances were investigated, which were $2 \mathrm{~mm}(\delta / r=0.034), 4 \mathrm{~mm}(\delta / r=0.068)$ and then $6 \mathrm{~mm}(\delta / r=0.102)$, respectively.

In addition, regarding the axial clearance parallel to the shaft axis. The axial clearance is the distance between the impeller outlet and the diffuser inlet. The first pump axial clearance $\Delta$ was set to be $1 \mathrm{~mm}$. This was achieved by manufacturing a small groove on the shaft to place a locking snap ring to lock the impeller in each pump stage with the selected axial clearance. This clearance was increased from $1 \mathrm{~mm}(\Delta / \mathrm{b}=0.166)$ to $2 \mathrm{~mm}(\Delta / \mathrm{b}=0.333)$ and then to $3 \mathrm{~mm}(\Delta / \mathrm{b}=0.5)$, respectively. The change of this axial clearance, in each pump stage, was achieved by moving the impeller locking snap ring $1 \mathrm{~mm}$ on the shaft to be fixed on the next shaft groove as shown in figure (1). Then, by moving the locking snap ring to the third position (groove) on the shaft, the third pump axial clearance $3 \mathrm{~mm}$ is achieved.

First of all, the borehole pump under investigation $\left(N_{s}=40.18\right)$ was tested with the selected first radial and axial clearances at $1450 \mathrm{rpm}$, which were $2 \mathrm{~mm}$ radial clearance $(\delta / \mathrm{r}=0.034)$ and $1 \mathrm{~mm}$ axial clearance $(\Delta / \mathrm{b}=0.166)$. Then, another two runs were performed for the pump at the same rotational speed, while changing the axial clearance from $2 \mathrm{~mm}(\Delta / \mathrm{b}=0.333)$ to $3 \mathrm{~mm}(\Delta / \mathrm{b}=0.5)$ while keeping the first radial clearance of $2 \mathrm{~mm}$ unchanged. Then, another three tests were run for the pump with the second radial clearance of $4 \mathrm{~mm} \quad(\delta / r=0.068)$ and the axial clearance of $1 \mathrm{~mm}$ $(\Delta / \mathrm{b}=0.166)$ and the others $2 \mathrm{~mm}$ and $3 \mathrm{~mm}$. Finally, another three tests were performed for the pump with the last radial clearance of $6 \mathrm{~mm}$ and with the three axial clearances $1 \mathrm{~mm}, 2, \mathrm{~mm}$ and $3 \mathrm{~mm}$, respectively. So the whole number of tests were nine.

\section{RESULTS AND DISCUSSION}

Investigations are carried out to plot the borehole pump performance curves at a constant pump rotational speed of $1450 \mathrm{rpm}$, while varying the axial and radia clearances. In the first test, the pump was tested and its performance curves were plotted with the first selected radial clearance of $2 \mathrm{~mm}$ and the first selected axial clearance along the shaft axis of $1 \mathrm{~mm}$. Figures $(2 \mathrm{a}, 2 \mathrm{~b} \& 2 \mathrm{c})$ show the pump performance curves as a relation between the pump head, power and efficiency with respect to its discharge in dimensionless forms. These dimensionless forms are related to the condition at the maximum efficiency point. The three figures show a normal borehole pump performance curves, similar to those of a normal centrifugal pump. With the increase of the pump discharge, the pump head decreases and the power increases slightly. The pump efficiency increases up to a certain limit and then, begins to decrease. The drop in the pump head is more than the increase in the
pump power. 
Figures $(3 a, 3 b \& 3 c)$ show the effect of changing the axial cle:arance from 1 to 2 to $3 \mathrm{~mm}$ at radial clearance of $2 \mathrm{~mm}$. Figure (3a) shows that the shut off head is maximum at $3 \mathrm{~mm}$ axial clearance, followed by $2 \mathrm{~mm}$ then $1 \mathrm{~mm}$, i.e. before the normal operating point, increasing the axial clearance increases the produced pump head. For discharge values more than the normai discharge, the increase of the axial clearance decreases the pump head.

Figure (3b), which is a dimensionless relation between the pov/er and the discharge, shows that before the normal operating point, no change is cbserved in the power ratio while changing the axial clearance. That is to say, the sarre power is required to drive the pump at reduced flows (below the operating point) whatever the axial clearance is. However, after the normal operating point, the p.mp power increases. Consequently, the pump efficiency, as shown in figure (3c), remains almost constant before the normal operating point but after this point the minimum pump axial clearance results in the highest pump efficiency.

Figures $(4 a, 4 b, 4 c)$ show the effect of changing the axial clearance from 1 to 2 to $3 \mathrm{~mm}$ at a radial clearance of $4 \mathrm{~mm}$. In this case, it is clear that increasing the axial clearance increases the produced pump head atter the normal sperating point. Before this point, the opposite occurs since the shut off nead produced with the lowest axial clearance is more than the one produced with the highest axial clearance. As an example the shut off head ratio. $\mathrm{H}_{\mathrm{H}} \mathrm{H}$, produced with $1 \mathrm{~mm}$ axia clearance is found to be 1.65 while it is found to be 1.3 with the $3 \mathrm{~mm}$ axial clearance. Figure (4b), shows that the power produced above the normal operating condition: is decreasing during the increase of the axial clearance. In figure $(\Delta c)$, the efficiency is increasing at high flows with the increase of the pump axial clearance. This is a very significant issue because the efficiency ratio, as shown in the figure at a discharce ratio of 1.6, with the $3 \mathrm{~mm}$ axial clearance was found to be $60 \%$. Ii was found to be $20 \%$ with $2 \mathrm{~mm}$ axial clearance and around $9 \%$ with the lowest tested axial clearance of $1 \mathrm{~mm}$

Figures $(5 a, 5 b, 5 c)$ show the effect of changing the axial clearance from 1 to 2 to $3 \mathrm{~mm}$ with the third pump radial clearance tested which wa; $6 \mathrm{~mm}$. In this case increasing the axial clearance to the maximum iested limit dezreases the produced head after the best efficiency point. Also, the snur off head wilh the maximum axial clearance is lower than the others. The power recuired to drive the pump, as shown in figure $(5 \mathrm{~b})$, is increasing with the increase in the pump disct arge after the normal point. As shown in figure $(5 \mathrm{c})$, the efficiency is the lowest with the maximum axial clearance.

It is well known that the flow between the imrielier outlet and the diffuser inlet is a spiral flow with constant actual absolute angie The results oblained; show that, the best combination found is to run the pump at the maximum radial clearance of $6 \mathrm{~mm}$ $(\delta / r=0.102)$ and $2 \mathrm{~mm}(\Delta \mathrm{b}=0.333)$ axial clearence. This is clea because of attaining the highest efficiency ratio of 0.65 at a discrio of 1.6 ; as shown in figure (4). This means that both the turbulence and thes losses at the impeller outlet are minimum. 
Since for a certain fixed pump rotational speed $\mathrm{N}$, a known diameter ratio, the discharge $Q$ of the cut impeller at or near the best efficiency point was determined experimentally. So, a relation between the diameter ratio and discharge ratio can be obtained as indicated by Nyiri [7] by using a certain correction factor $\mathrm{k}$. This equation is given by:

$$
\mathrm{D} / \mathrm{D}_{0}=1-\mathrm{k}\left(1-\mathrm{Q}_{\mathrm{Q}} / \mathrm{Q}_{0}\right)
$$

Where, $\left(D_{0} \& Q_{0}\right)$ refer to the pump at the first radial and axial clearances of $\delta=2 \mathrm{~mm}$ $(\delta / r=0.034)$ and $\Delta=1 \mathrm{~mm}(\Delta / \mathrm{b}=0.166)$, respectively.

From the test results found in this research work, the values of the correction factor $k$ were determined. The relation between $D / D_{0} \& Q / Q_{0}$ is shown in figure (6), which includes a comparison between these results and the corresponding values for previous investigators as well.

The following table shows the relation between $\left(D / D_{0}\right)$ and $\left(Q / Q_{0}\right)$ found from the results obtained in this research.

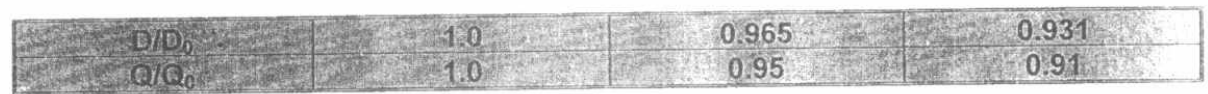

This relation is shown in figure (6); which shows a close agreement with the results obtained by Stepanoff [8] at the same range of the pump specific speed.

\section{CONCLUSIONS}

From the previously tested cases, it is clear that changing either the radial or the axial clearances or both has a remarkable effect on the pump performance. So, although it was expected that the pump head is decreasing with the increase of its discharge, however, this can be highly affected by changing the pump axial clearance. The best combination found, is to run the pump at discharge values above the corresponding values at the normal operating point, with the maximum radial clearance of $6 \mathrm{~mm}(\delta / r=0.102)$ and with $2 \mathrm{~mm}(\Delta / \mathrm{b}=0.333)$ axial clearance. This will help in decreasing the pump power and hence increasing its efficiency.

\section{REFERENCES}

[1] I. J. Karassik, W.C. Krutzsch, W.H. Fraser. "Pump Handbook". McGraw Hill book Company, 1976

[2] G. Vetter, W. Wirth. "Suitability of eccentric helical pumps for turbid water deep well pumping".

Solar Energy (ISSN-0038) vol. 51, no. 3, pp. 205-214, 1993

[3] T. F. Scherer, "Irrigation Water Pumps"

North Dakota State University, NDSU Extension Service, AE-1057, April 1993. 
[4] W. S. Tinney, "Venting Deep Well Pumps"

Target Technology Ltd, Chemical Enginenting. PP 83-85, November 30, 1981.

[5] D.N. Alcock, "Application of Variable-Frequency Drives To Deep well

Submersible Pumps".

International Petroleum Engineering pp-36-44, March 15, 1980

[6] A. M. El-Sibaie, "Another Approach To The Equations of Reduced Impeller Diameters of Radial Flow Centrifugai Pumes

The Bulletin of the Faculty of Engineering Ain Shams University, No. 4, pp 243-251, 1970.

[7] A. Nyiri, "On The Reduction of tonpelar Drameter of Radial Flow Centrifugal Pumps".

International symposium, pumps in power statons, Braunschweig, Germany, 1966

[8] A. J. Stepanoff, "Centrifugal and Axiat Ficin Plimps"

$2^{\text {nd }}$ edition, John Wiley \& Sons, 1957 


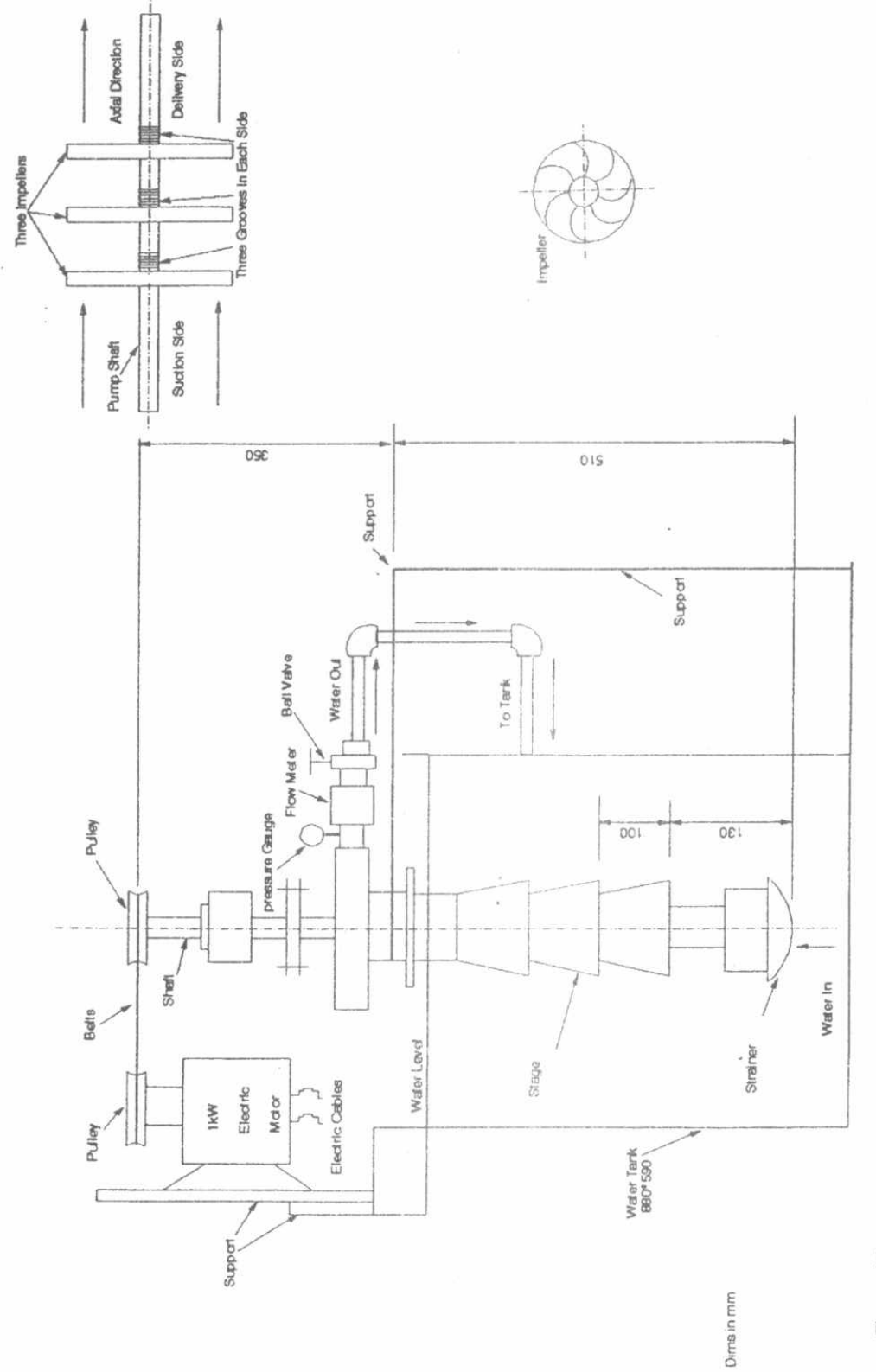



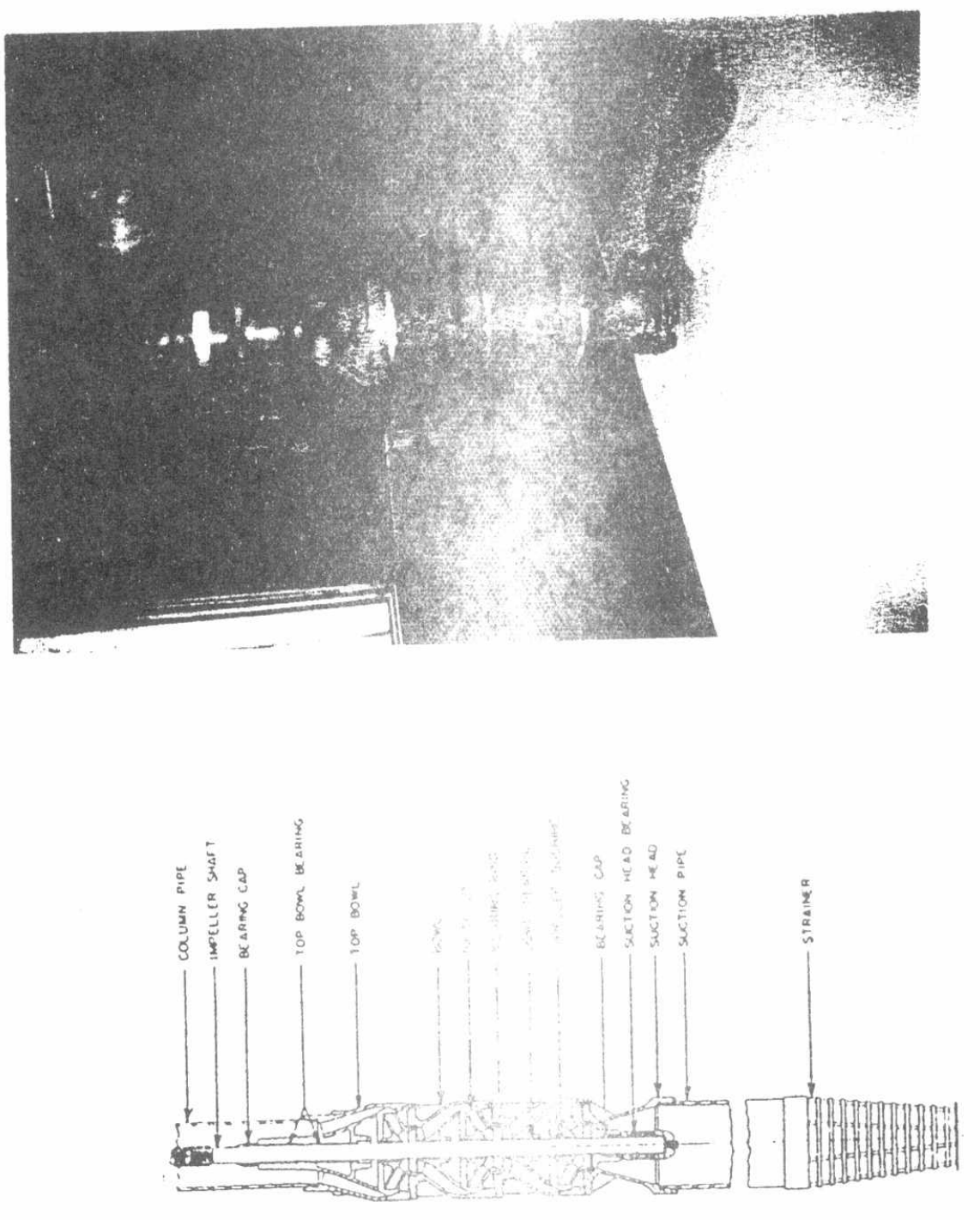

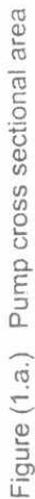




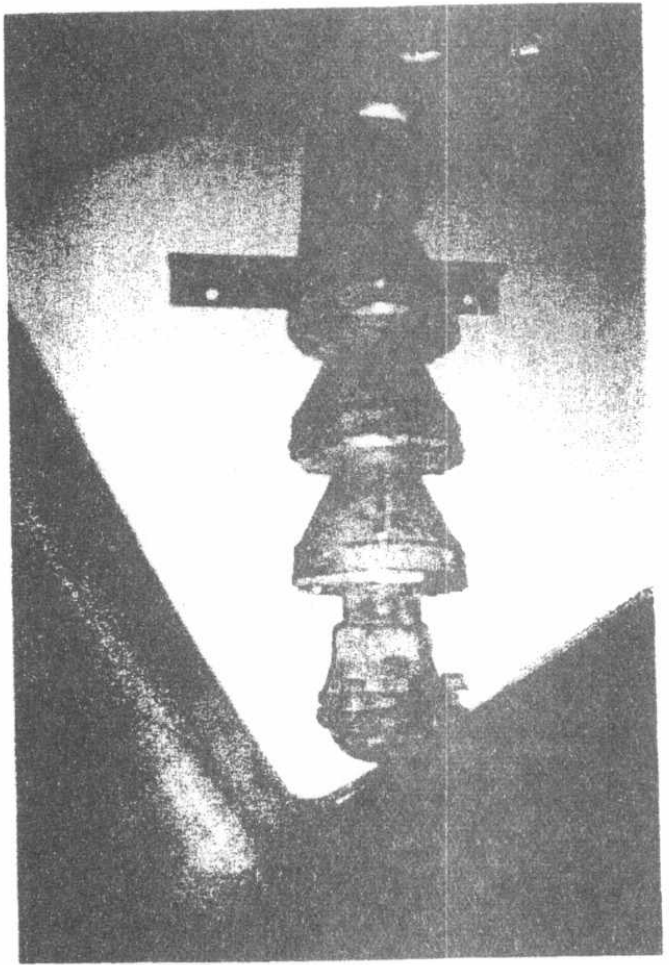

Photo (2). The Pump and its suction valve and strainer.

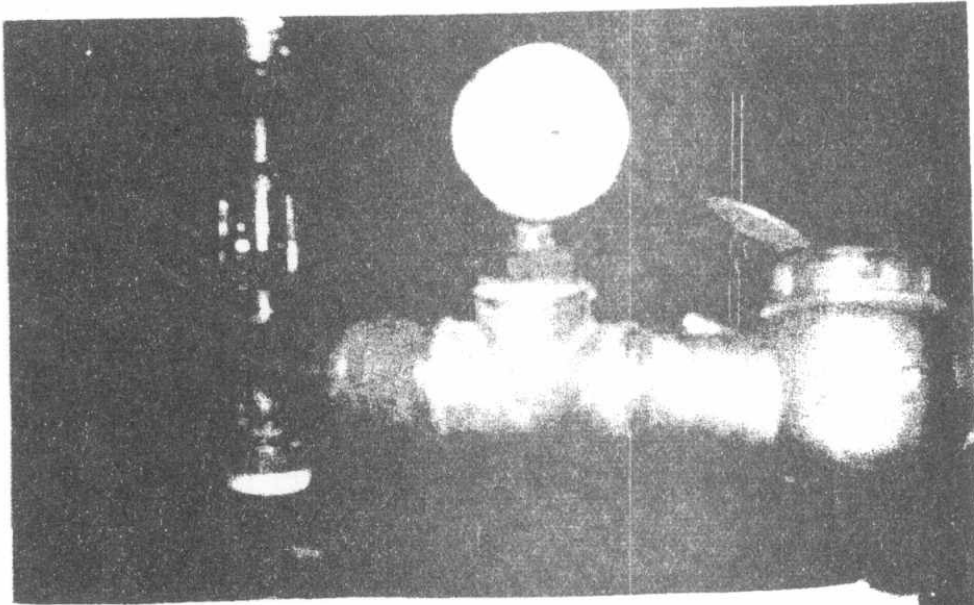

Photo (3). The pump delivery line, flow meter and the pressure gauge. 


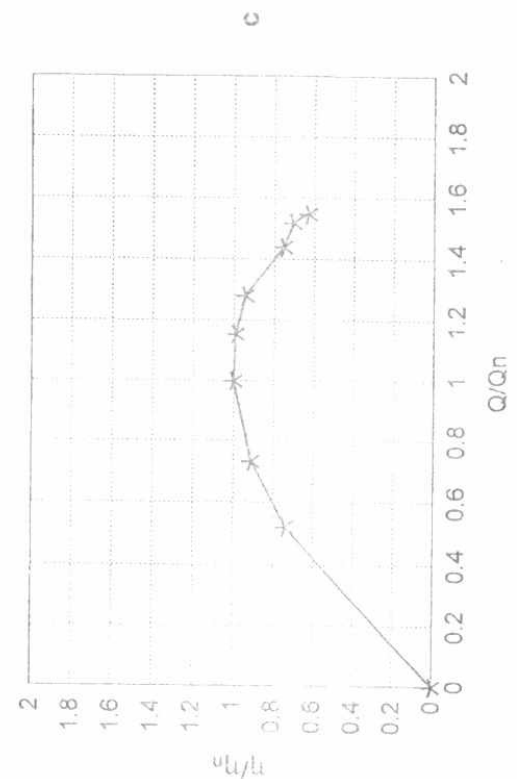

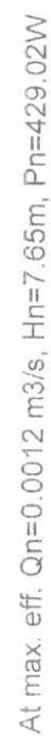
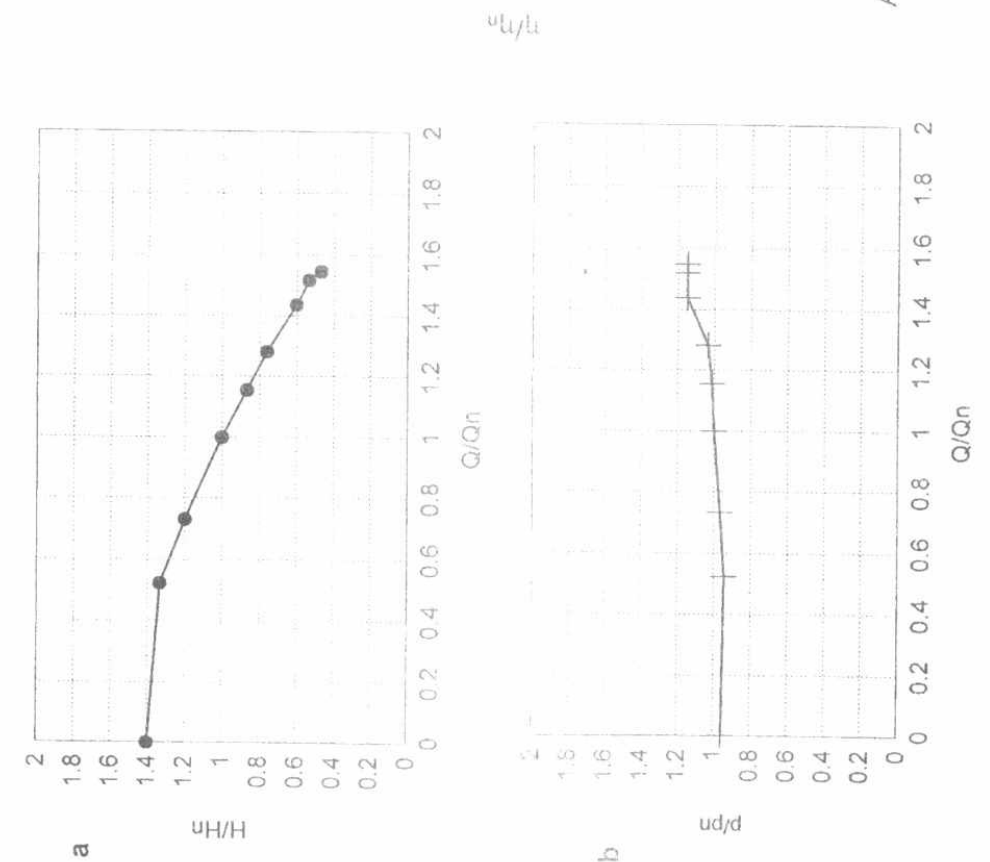
0

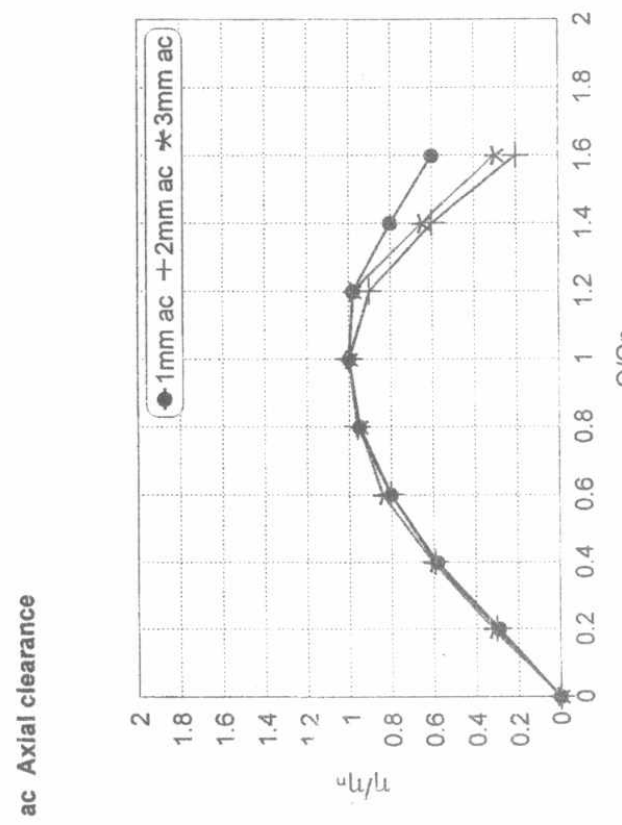

Y

ऽ

พ

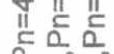

हू है

它宁

NiI

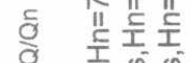

si w

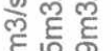

సิ फ्ల

등ㄷㅇㅇㅇㅁ

는 인

ฮิ ฮิ

ชิ ชิ

E E ह

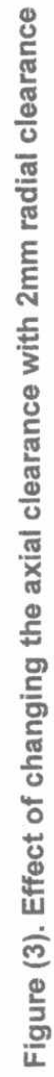

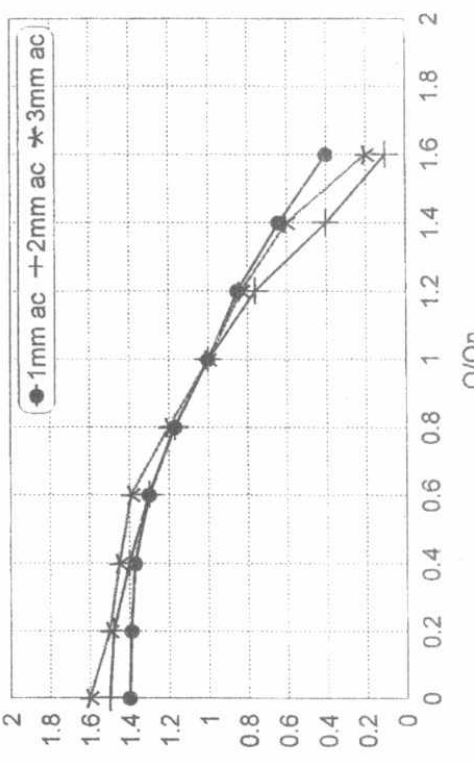

UH/H

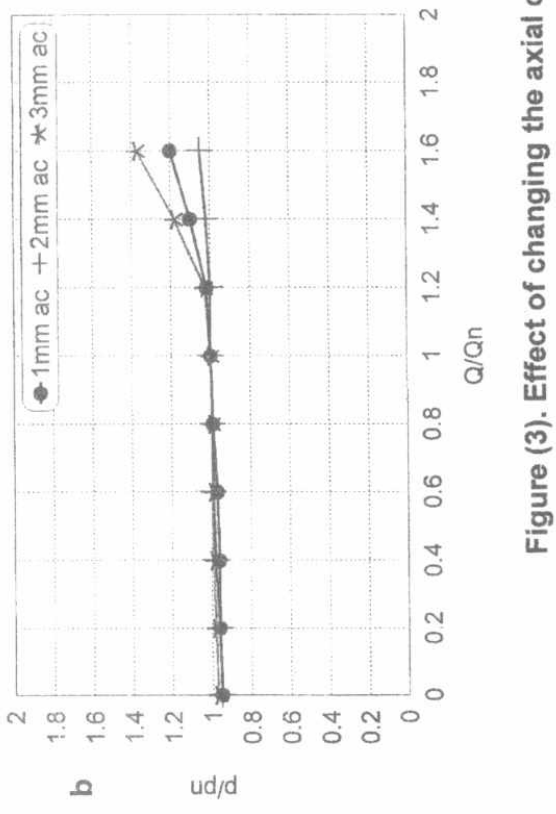


u
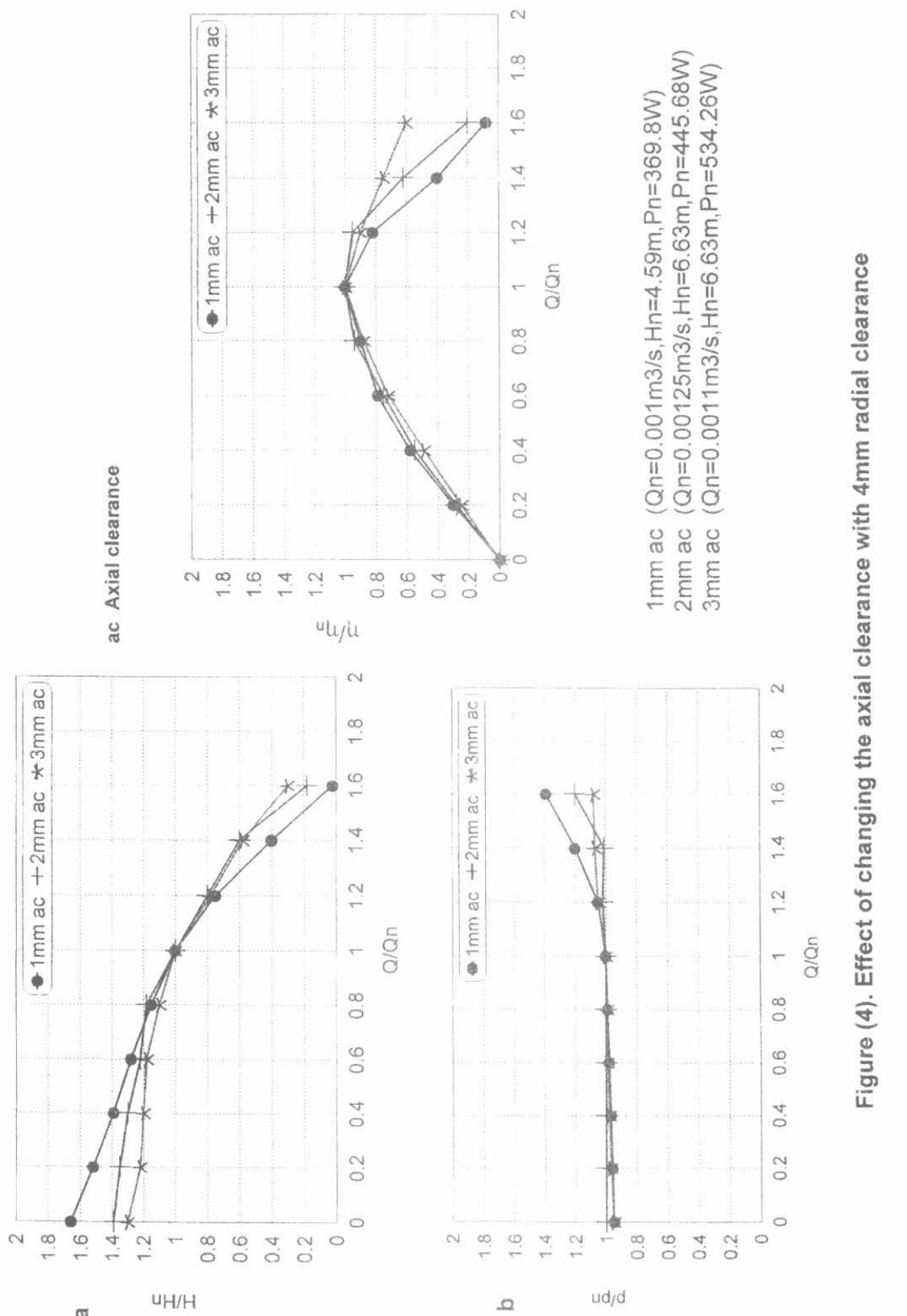


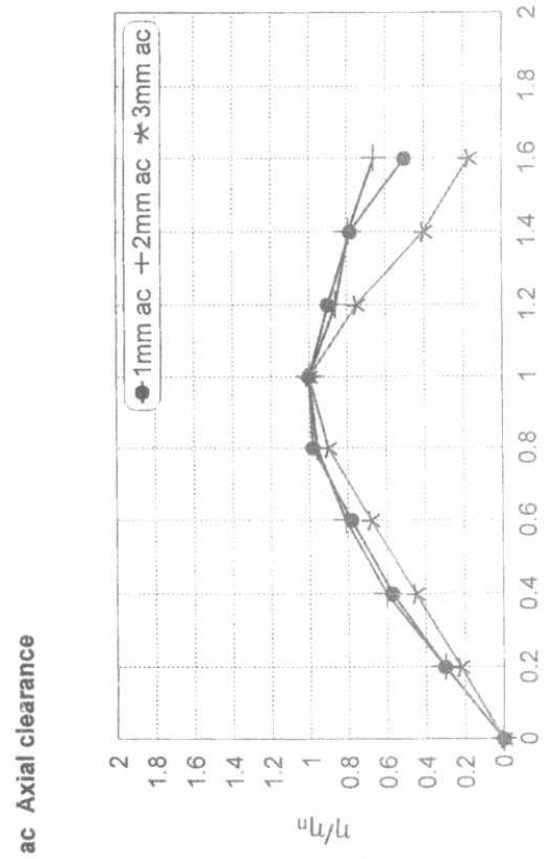

依

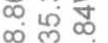

品

II

ह ह

है

फी की

II 도에

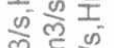

है है

둥형

II II II

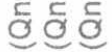

ن

हू ह हू ह

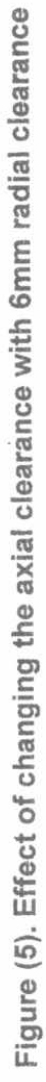
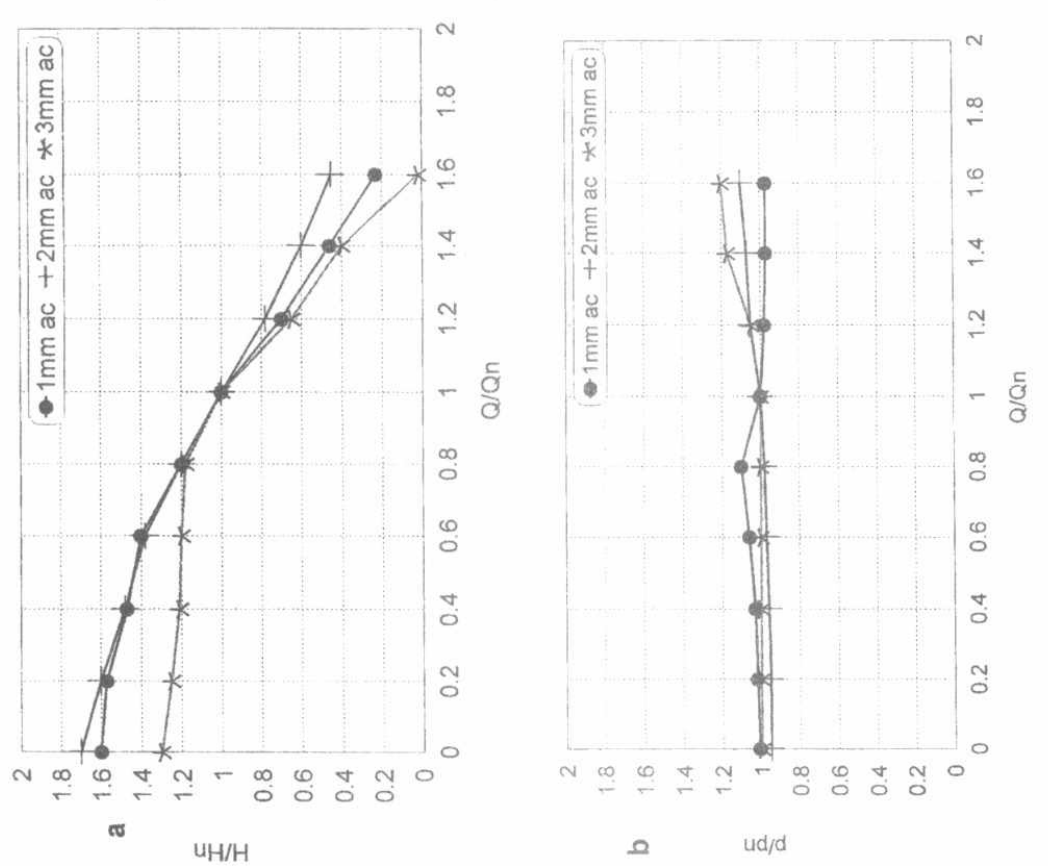


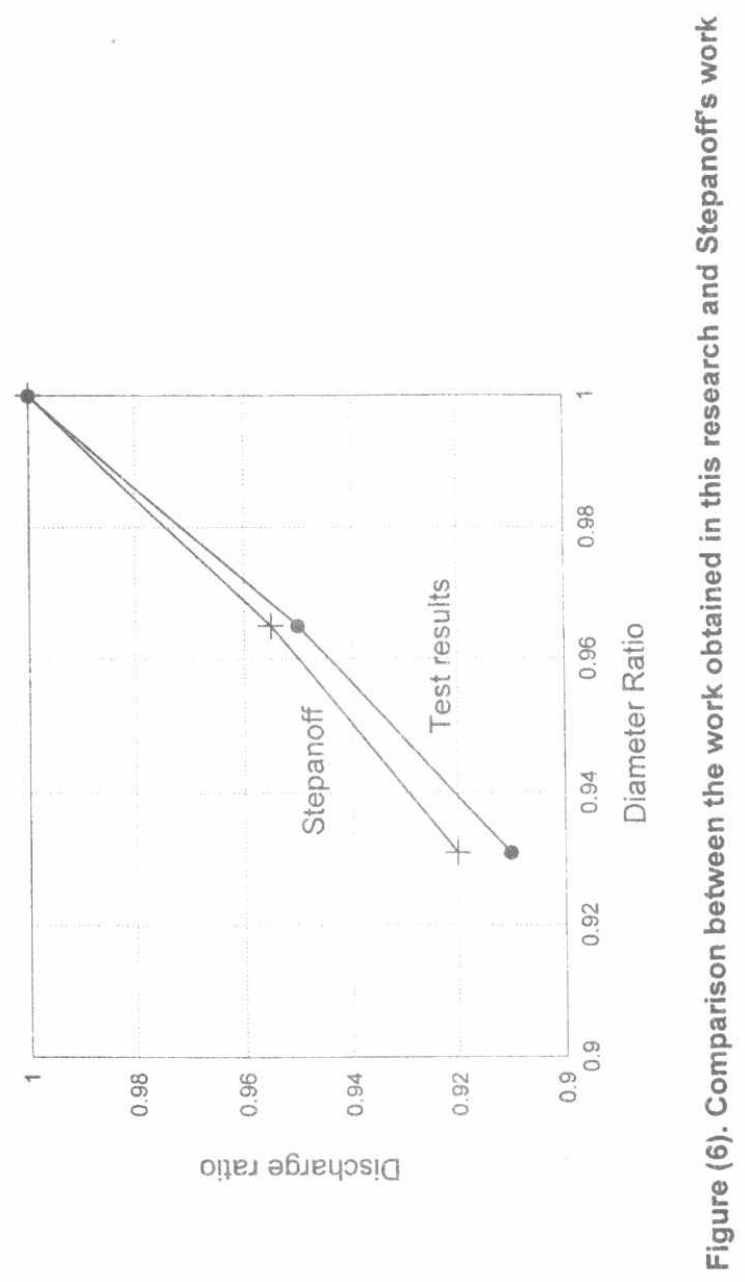

